\title{
Influence of the Obtaining Method on the Properties of Amorphous Aluminum Compounds
}

\author{
Aliya N. Mukhamed'yarova *, Oksana V. Nesterova, Kirill S. Boretsky, Juliya D. Skibina, \\ Avgustina V. Boretskaya, Svetlana R. Egorova and Alexander A. Lamberov
}

Alexander Butlerov Institute of Chemistry, Kazan Federal University, Kazan 420008, Russia; OVNesterova@kpfu.ru (O.V.N.); KSBoretsky@kpfu.ru (K.S.B.); JDSkibina@stud.kpfu.ru (J.D.S.); ger-avg@mail.ru (A.V.B.); svetlana.egorova@kpfu.ru (S.R.E.); alexander.lamberov@kpfu.ru (A.A.L.)

* Correspondence: anm03@list.ru; Tel.: +7-960-051-3178

Received: 1 December 2018; Accepted: 10 January 2019; Published: 14 January 2019

\begin{abstract}
Amorphous aluminum compounds are formed during the synthesis of the $\gamma-\mathrm{Al}_{2} \mathrm{O}_{3}$ catalyst precursor. Amorphous compounds influence on the alumina catalyst variously due to different physicochemical properties, which depend on the method of their preparation. In this research, the comparative analysis of physicochemical properties of amorphous aluminum compounds that were obtained by the precipitation method, the thermal decomposition of aluminum nitrate, and alcoxide hydrolysis product were studied. It is the first time that a new method for calculating of quantitative phase composition of amorphous aluminum compounds using the $\mathrm{X}$-ray powder diffraction, thermogravimetric and differential scanning calorimetry analysis, mass-spectrometry, and $\mathrm{CHN}$-analysis was described. Properties of obtaining samples were studied using scanning electron microscopy, low-temperature nitrogen adsorption, and temperature programmed desorption of ammonium analyses. The methods of precipitation and thermal decomposition of aluminum nitrate allows for obtaining non-porous samples consisting of a mixture of amorphous phases (hydroxide and basic salt) that contain the metals impurities and have low acidity of the oxides obtained from them. The highly porous amorphous alumina formed by the thermal decomposition of the alcoxide hydrolysis product with the least amount of impurities and a high acidity of the surface was observed.
\end{abstract}

Keywords: amorphous aluminum compound; alumina catalyst; alumina; pseudoboehmite; precipitation; thermal decomposition

\section{Introduction}

Gamma-alumina $\left(\gamma-\mathrm{Al}_{2} \mathrm{O}_{3}\right)$ is widely used in the petrochemical industry as a catalyst, catalyst carrier, and adsorbent. $\gamma-\mathrm{Al}_{2} \mathrm{O}_{3}$ is formed during the thermal decomposition of the boehmite [1], obtained from the sol-gel method from bayerite [2], bauxite [3], salts and salt-like aluminum compound [4-6], amorphous aluminum oxide, and hydroxide [5,7]. Depending on the nature and characteristics of the precursor, it is possible to regulate the physicochemical properties of $\gamma$-alumina. One of the most important characteristics of the catalyst precursor is the properties of its surface, such as morphology, porous system, and acidity.

On an industrial scale, $\gamma-\mathrm{Al}_{2} \mathrm{O}_{3}$ is predominantly produced by the thermal decomposition of pseudoboehmite (PB). There are many methods for the synthesis of $\mathrm{PB}$, for example, a hydrothermal treatment of gibbsite or alumina, a precipitation from solution salts under hydrothermal conditions [8,9], and others. However, the most common methods of PB obtaining are the hydrolysis of aluminum alkoholates [10] and the precipitation of aluminum hydroxide from Al-containing acidic solutions by a base [11]. These methods allow for controlling the phase composition and physicochemical properties of the obtained aluminum hydroxides. In both cases, the formation of 
amorphous compounds is observed in addition to the target product due to the forming of incomplete hydrolysis products in the first case and the organic residues in the second case, in accordance with Scheme 1.

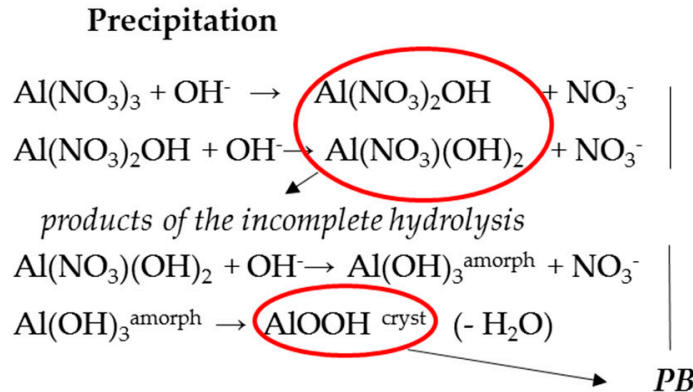

Hydrolysis of aluminum alcoholate

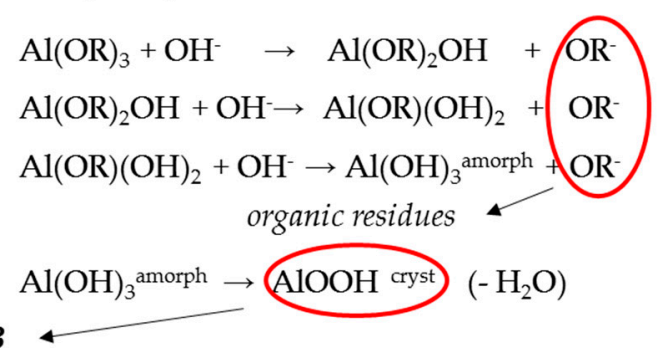

Scheme 1. Forming of X-ray amorphous aluminum compounds by the precipitation and hydrolysis.

Currently, the amorphous aluminum compounds have been studied poorly and they are described in a small amount of research works. However, these compounds affect the properties of $\gamma-\mathrm{Al}_{2} \mathrm{O}_{3}$ catalysts.

On the one hand, the amorphous component presence as a part of alumina catalyst precursor in various petrochemical processes is unfavorable. The amorphous compound is a gel that reduced the filterability of the precipitation product and complicated the washing of PB from impurity ions $(\mathrm{Na}, \mathrm{Fe}$, etc.) that are catalytic poisons. In addition, the amorphous component has a low specific surface area [12]. Therefore, the amount of the amorphous component in the PB is reduced at the synthesis process.

On the other hand, the amorphous component has a positive effect on the catalyst. An amorphous base aluminum salts provide the plastic properties of the catalyst precursor during a molding. The salts decompose with the formation a new binding phase after the calcination [13]. In our previous works [14], we have already shown that it is possible to improve the properties of catalyst for skeletal isomerization of $\mathrm{n}$-butenes to isobutylene by transforming the amorphous component using hydrothermal treatment.

There are several ways to obtain the amorphous aluminum compounds: a calcination of the aluminum salts [7], the hydrolysis of the aluminum alcoholates [15], and the precipitation from Al-containing solutions by the base $[7,16]$. As a result, various non-crystalline aluminum compounds are formed differing in a phase composition and the physicochemical properties of surface. High-purity amorphous aluminum hydroxide containing the organic residues is obtained by the hydrolysis of organoaluminum compound. The residues of salts precursor are also presented in the structure of amorphous compounds that are formed by the precipitation and the thermal decomposition of aluminum salts, for example, nitrate, according to the Scheme 2.

$$
\begin{aligned}
& \text { Thermal decomposition } \\
& {\left[\mathrm{Al}\left(\mathrm{H}_{2} \mathrm{O}\right)_{6}\left(\mathrm{NO}_{3}\right)_{3}\right] \cdot 3 \mathrm{H}_{2} \mathrm{O} \stackrel{80^{\circ} \mathrm{C}}{\rightarrow} \mathrm{Al}\left(\mathrm{H}_{2} \mathrm{O}\right)_{6}\left(\mathrm{NO}_{3}\right)_{3}\left(-\mathrm{H}_{2} \mathrm{O}\right)} \\
& \mathrm{Al}\left(\mathrm{H}_{2} \mathrm{O}\right)_{6}\left(\mathrm{NO}_{3}\right)_{3}{ }_{\text {products of incomplete thermal decomposition }}^{>170^{\circ} \mathrm{C}} \rightarrow{\left.\mathrm{Al}\left(\mathrm{H}_{2} \mathrm{O}\right)_{\times}\left(\mathrm{NO}_{3}\right)_{\mathrm{Y}}\right)}_{\left(-\mathrm{NO}-\mathrm{H}_{2} \mathrm{O}\right)}
\end{aligned}
$$

Scheme 2. Forming of X-ray amorphous aluminum compound by the thermal decomposition.

These schemes are debatable, and further research is needed to clarify them.

Therefore, the purpose of our research was a comparative analysis of physicochemical surface properties of the amorphous aluminum compounds that were obtained by the methods, such as the 
precipitation method, the thermal decomposition of aluminum nitrate, and alcoxide hydrolysis product. We also propose a new method for calculating the phase composition of the amorphous aluminum compounds using a group of XPRD, TG-DSC, mass spectrometry (MS), and CHN-analysis methods.

\section{Materials and Methods}

Three samples of the amorphous aluminum compounds were obtained by the various methods. Sample 1 (S1) was carried out by the precipitation from $0.25 \mathrm{~g} / \mathrm{mL} \mathrm{Al}\left(\mathrm{NO}_{3}\right)_{3} \cdot 9 \mathrm{H}_{2} \mathrm{O}$ (analytically pure, according to the State standard GOST 3757-75 [17] contains $<0.004 \mathrm{wt} \% \mathrm{Fe},<0.05 \mathrm{wt} \% \mathrm{~K}+\mathrm{Na}$ ) solution by ammonia water (chemically pure, according to the State standard GOST 3760-79 [17] contains $<0.0001 \mathrm{wt} \% \mathrm{Fe},<0.0001 \mathrm{wt} \% \mathrm{Mg}+\mathrm{Ca},<0.001 \mathrm{wt} \% \mathrm{CO}_{3}{ }^{2-}$ ) at $\mathrm{pH}=6.0$ and the room temperature without the stabilization and aging stages. The obtained gel-like product was centrifuged $20 \mathrm{~min}$ in $700 \mathrm{~mL}$ of $\mathrm{H}_{2} \mathrm{O} 4$ times to remove the ammonium nitrate formed during the precipitation. Subsequently, sample S1 was drying during $2 \mathrm{~h}$ at the $100-105^{\circ} \mathrm{C}$. A precipitate with the maximum amount of basic salt was obtained. Sample 2 (S2) was synthesized by heat treatment of $\mathrm{Al}\left(\mathrm{NO}_{3}\right)_{3} \cdot 9 \mathrm{H}_{2} \mathrm{O}$ (analytically pure, the State standard GOST 3757-75) at $350^{\circ} \mathrm{C}$ during $1 \mathrm{~h}$ at an atmospheric pressure. Sample 3 (S3) was obtained by heat treatment at $550{ }^{\circ} \mathrm{C}$ during $2 \mathrm{~h}$ at the atmospheric pressure from non-crystalline aluminum hydroxide (impurities: $0.52 \mathrm{wt} \% \mathrm{C},<0.001 \mathrm{wt} \% \mathrm{Na}, \mathrm{Mg}$ and $\mathrm{Fe}$ ) that was obtained by the method of hydrolysis of aluminum isopropoxide (chemically pure, $<0.0001 \mathrm{wt} \% \mathrm{Na}$, $\mathrm{Mg}, \mathrm{Fe}$ ) by water vapor. The hydrolysis of aluminum isopropoxide with water vapor was carried out by the following equation: $\mathrm{Al}\left(i-\mathrm{C}_{3} \mathrm{H}_{7} \mathrm{O}\right)_{3}$ liquid $+3 \mathrm{H}_{2} \mathrm{O}$ vapor $=\mathrm{Al}(\mathrm{OH})_{3}$ solid $+3 \mathrm{C}_{3} \mathrm{H}_{7} \mathrm{OH}^{\text {vapor }}$

The resulting aluminum hydroxide $\left(\mathrm{Al}(\mathrm{OH})_{3}{ }^{\text {solid }}\right)$ (Figure $\mathrm{S} 1$ in the Supplementary Material) is an amorphous compound with organic residues, which was heat treated at $550{ }^{\circ} \mathrm{C} / 2 \mathrm{~h}$ up to their complete removal.

The element composition of the samples was made using a system for the CHNS/O analysis of PE 2400-II (Perkin Elmer, Waltham, MA, USA) and an iCAP Q inductively coupled plasma mass spectrometer (ICP-MS) (Thermo Fisher Scientific, Waltham, MA, USA).

The phase composition of samples was determined using X-ray powder diffraction (XRPD) by a MiniFlex 600 diffractometer (Rigaku, Tokyo, Japan) equipped with a D/teX Ultra detector. In this experiment, $\mathrm{Cu} \mathrm{K} \alpha$ radiation $(40 \mathrm{kV}, 15 \mathrm{~mA})$ was used and data was collected at room temperature in the range of $2 \theta$ from $2^{\circ}$ to $100^{\circ}$ with a step of $0.02^{\circ}$ and exposure time at each point of $0.24 \mathrm{~s}$ without sample rotation. The phase concentrations were determined using the thermal analysis (TA; Netzsch STA-449C Jupiter, Selb, Germany). The TA was carried out in a way that is capable of recording the thermogravimetric (TG), derivative thermogravimetric (DTG), and differential thermal analysis (DTA) curves simultaneously. The samples were heated in the temperature range of $30-1000{ }^{\circ} \mathrm{C}$ at the uniform heating rate of $10{ }^{\circ} \mathrm{C} / \mathrm{min}$ in an argon flow. Concentrations of aluminum hydroxides were calculated from the amount of the water that was released during the aluminum hydroxides dehydration and dehydroxilation. Mass spectrometry (MS) analysis was carried out at the heating of samples at the same rate in He current using of a ThermoStar GSD 320 T gas analyzer (Pfeiffer Vacuum, Nashua, NH, USA).

The measurements by scanning electron microscopy (SEM) were carried out with an EVO 50XVP electron microscope combined with an INCA 350 energy-dispersive spectrometer (Carl Zeiss, Upper Cohen, Germany). The spectrometer resolution was $130 \mathrm{eV}$. The analysis was carried out at an acceleration voltage of $20 \mathrm{kV}$ and flange back distance of $8 \mathrm{~mm}$.

The specific surface area $S_{\mathrm{BET}}$ (calculated with the Brunauer-Emmett-Teller method [18]) and the pore volume $V$ (calculated by the last point of isotherm [18]) were determined using a multipurpose Autosorb-iQ analyser (Quantachrome Instruments, Boynton Beach, FL, USA). Adsorption isotherms were obtained at $-196{ }^{\circ} \mathrm{C}(77 \mathrm{~K})$ after the degassing of samples at $150{ }^{\circ} \mathrm{C}$ under the residual pressure of $0.013 \mathrm{~Pa}$. The pore volumes' distributions over the pore diameters were calculated from the curve of desorption isotherm by using the standard Barrett-Joyner-Halenda mechanism $\left(\mathrm{V}_{\mathrm{BJH}}\right)$ [18]. 
The surface acidity of S3 sample and alumina derived from the S1 and S2 samples was analyzed by the method of temperature-programmed desorption of ammonia (TPD- $\mathrm{NH}_{3}$ ) on a flow-type instrument with a thermal conductivity detector ChemBet Pulsar (Quantachrome Instruments, Boynton Beach, FL, USA). Before ammonia adsorption, the sample was degassed by heating up to $550{ }^{\circ} \mathrm{C}$ in a helium flow. The adsorption step was carried out in a stream of ammonia for $30 \mathrm{~min}$ at a temperature of $100^{\circ} \mathrm{C}$. The physically adsorbed ammonia was removed by helium flow at $100{ }^{\circ} \mathrm{C}$ for $30 \mathrm{~min}$. After analysis, the sample was cooled to room temperature in a helium flow. Temperature programmed desorption of ammonia was carried out from room temperature to $700{ }^{\circ} \mathrm{C}$ at a rate of $10^{\circ} \mathrm{C} / \mathrm{min}$. Calculations of TPD- $\mathrm{NH}_{3}$ data on the distribution of acid sites were performed according to the method that is given in the research [19].

\section{Results and Discussion}

All the samples of amorphous compounds obtained by different methods contain $95-99$ wt \% of the basic elements of $\mathrm{Al}, \mathrm{H}, \mathrm{O}$, and differ from the impurity composition (Table 1). The most amount of impurities is identified in sample $\mathrm{S} 2$ obtained by heat treatment of aluminum nitrate $\mathrm{Al}\left(\mathrm{NO}_{3}\right)_{3} \cdot 9 \mathrm{H}_{2} \mathrm{O}$, which consisted of the nitrate according to the State standard (GOST 3757-75). Sample S3 was synthesized from the high-purity product of the hydrolysis of aluminum alcoxide. Therefore, after calcining, S3 contains the minimum amount of $\mathrm{Li}, \mathrm{C}, \mathrm{N}, \mathrm{Na}$, and $\mathrm{Mg}$ impurities. Samples S1 and $\mathrm{S} 2$ include a considerable amount of nitrogen in the form of $\mathrm{NO}_{3}{ }^{3-}$ group (Table 1). S1 is the product by the precipitation from the solution of aluminum nitrate with ammonia where a nitrogen in its structure remains due to incomplete hydrolysis. S2 is the product of thermal decomposition of aluminum nitrate, the heat treatment leads to the incomplete release of nitrogen oxides from the nitrate when residual water molecules are still present [6].

Table 1. Impurity content of samples S1-S3.

\begin{tabular}{|c|c|c|c|c|c|c|c|c|}
\hline \multirow{2}{*}{ Sample } & \multirow{2}{*}{ Obtaining Method } & \multirow{2}{*}{ Conditions } & \multicolumn{6}{|c|}{ Content (wt \%) } \\
\hline & & & $\mathrm{Na}$ & $\mathrm{Mg}$ & Li & $\mathrm{C}$ & $\mathbf{N}$ & $\mathbf{F e}$ \\
\hline S1 & Precipitation & $\mathrm{pH}=6.00$ & $<0.009$ & $<0.001$ & 0.000 & 0.41 & 4.57 & $<0.009$ \\
\hline S2 & $\begin{array}{l}\text { Heat treatment of } \\
\text { aluminum nitrate }\end{array}$ & $\begin{array}{c}350{ }^{\circ} \mathrm{C}, \\
1 \mathrm{~h}\end{array}$ & 0.017 & 0.015 & 0.005 & 0.21 & 1.71 & 0.011 \\
\hline S3 & $\begin{array}{l}\text { Heat treatment of } \\
\text { hydrolysis product }\end{array}$ & $\begin{array}{l}550^{\circ} \mathrm{C}, \\
2 \mathrm{~h}\end{array}$ & 0.007 & 0.011 & 0.000 & $\sim 0.05$ & 0.00 & 0.022 \\
\hline
\end{tabular}

Samples S1-S3 are identified on the diffractograms as the X-ray amorphous aluminum compounds. A wide halo effect at the range of $20^{\circ}-40^{\circ}$ of the S2 and S3 and of S1 are shown in Figure 1. The diffractogram of $S 1$ is characterized by the diffuse diffraction lines of $\mathrm{PB}$ at $20^{\circ}-70^{\circ}$ with $d / I_{(120)}=$ $0.316 \mathrm{~nm}, d / I_{(031)}=0.235 \mathrm{~nm}, d / I_{(200)}=0.177 \mathrm{~nm}, d / I_{(002)}=0.143 \mathrm{~nm}($ JCPDS Card 00-021-1307), and a diffraction line at $8^{\circ}$ with the $d / I_{(100)}=1.203 \mathrm{~nm}$ of the aluminum complex $\mathrm{Al}_{x}(\mathrm{OH})_{y}\left(\mathrm{NO}_{3}\right)_{z}\left(\mathrm{NH}_{4}\right)$ (JCPDS Card 01-080-7534) (Figure 1). The presence of PB of the sample S1 is also confirmed by TG-DSC and MS analyses. According to the TG-DSC data, PB is exhibited by a shoulder of the II endothermic effect on the DSC curve of sample S1 at the temperature of $397-570{ }^{\circ} \mathrm{C}$ with a mass loss $(\Delta m)$ of 3.63 wt $\%$, which is accompanied by the release of $\mathrm{H}_{2} \mathrm{O}$ and $\mathrm{NO}$ (Figure 2a,b):

$$
\mathrm{Al}_{2} \mathrm{O}_{3} \cdot n \mathrm{H}_{2} \mathrm{O} \stackrel{400-550{ }^{\circ} \mathrm{C}}{\longrightarrow} \gamma-\mathrm{Al}_{2} \mathrm{O}_{3}+n \mathrm{H}_{2} \mathrm{O} \uparrow
$$

On the DSC curves of all samples, two endothermic effects and the exothermic effect (Figure 2a-f, Table 2) are observed due to the following transformations [20,21]:

I endothermic effect : $\mathrm{Al}_{2} \mathrm{O}_{3} \cdot 3 \mathrm{H}_{2} \mathrm{O}^{\text {amorph }} \stackrel{200-300{ }^{\circ} \mathrm{C}}{\longrightarrow} \mathrm{Al}_{2} \mathrm{O}_{3}{ }^{\text {amorph }}+3 \mathrm{H}_{2} \mathrm{O} \uparrow$ 
II endothermic effect : $\mathrm{Al}_{2} \mathrm{O}_{3} \cdot x \mathrm{H}_{2} \mathrm{O} \cdot y \mathrm{NO}^{\text {amorph }} \stackrel{300-400{ }^{\circ} \mathrm{C}}{\longrightarrow} \mathrm{Al}_{2} \mathrm{O}_{3}$ amorph $+x \mathrm{H}_{2} \mathrm{O} \uparrow+y \mathrm{NO} \uparrow$

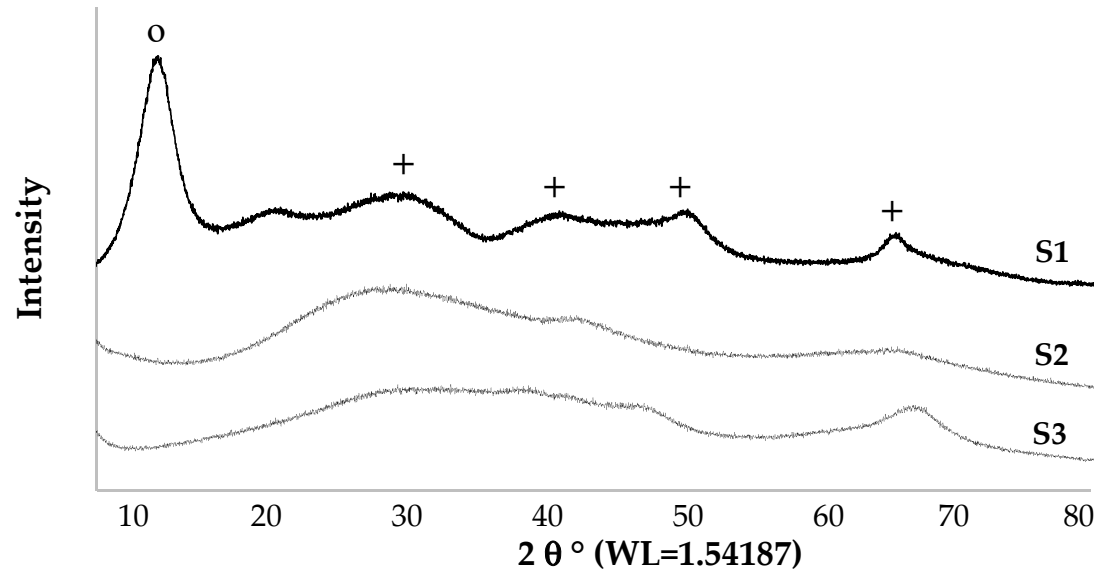

Figure 1. Diffractograms of samples S1-S3 (+, PB; o, aluminum complex).

The I endothermic effect corresponds to the release of water from the porous system of samples at the temperature up to $200{ }^{\circ} \mathrm{C}$ and during thermal decomposition of amorphous aluminum hydroxide $\mathrm{Al}_{2} \mathrm{O}_{3} \cdot x \mathrm{H}_{2} \mathrm{O}$ amorph above $200{ }^{\circ} \mathrm{C}$. The II endothermic effect at the $321-495{ }^{\circ} \mathrm{C}$ is identified as the thermal decomposition of the basic aluminum salts $\mathrm{Al}_{2} \mathrm{O}_{3} \cdot x \mathrm{H}_{2} \mathrm{O} \cdot y \mathrm{NO}$ amorph due to the release of $\mathrm{H}_{2} \mathrm{O}$ and NO (Table 2, Figure 2a-d), which corresponds to $m / z=18$ and 30, respectively, on the mass spectra.

The exothermic effect on the DSC curves is due to phase transformation low-temperature $\mathrm{Al}_{2} \mathrm{O}_{3}$ to high-temperature oxide without changing the mass (Figure 2a-f, Table 2), according to the following scheme [20]: $\mathrm{Al}_{2} \mathrm{O}_{3}$ amorph $\rightarrow \gamma-\mathrm{Al}_{2} \mathrm{O}_{3} \rightarrow \theta-\mathrm{Al}_{2} \mathrm{O}_{3} \rightarrow \alpha-\mathrm{Al}_{2} \mathrm{O}_{3}$. The amorphous alumina $\left(\mathrm{Al}_{2} \mathrm{O}_{3}\right.$ amorph $)$ is formed due to thermal decomposition of $\mathrm{X}$-ray amorphous aluminum hydroxide and basic aluminum salts [7]. The obtained from $\mathrm{PB} \gamma-\mathrm{Al}_{2} \mathrm{O}_{3}$ is transformed to high-temperature alumina without a visible exothermic effect on the S1 DSC curve $[1,4,7,12,22]$ (Figure 2a,b).

Table 2. TG-DSC and mass spectrometry (MS) analyses results of samples S1-S3.

\begin{tabular}{|c|c|c|c|c|c|c|c|c|}
\hline \multirow{3}{*}{ Sample } & \multirow{3}{*}{$\begin{array}{l}\text { Obtaining } \\
\text { Method }\end{array}$} & \multirow{3}{*}{ Conditions } & \multicolumn{4}{|c|}{ Endothermic Effects } & \multirow{2}{*}{\multicolumn{2}{|c|}{ Exothermic Effect }} \\
\hline & & & \multicolumn{2}{|c|}{ I Effect } & \multicolumn{2}{|c|}{ II Effect } & & \\
\hline & & & $\begin{array}{c}T_{\mathrm{p}} \\
\left(T_{\mathrm{b}}-T_{\mathrm{f}}^{*}\right)\left({ }^{*} \mathrm{C}\right)\end{array}$ & $\begin{array}{c}\Delta m \\
(w t \%)\end{array}$ & $\begin{array}{c}T_{\mathrm{p}} \\
\left(T_{\mathrm{b}}-T_{\mathrm{f}}\right)\left({ }^{\circ} \mathrm{C}\right)\end{array}$ & $\begin{array}{c}\Delta m \\
(\mathbf{w t} \%)\end{array}$ & $T_{\mathrm{p}},{ }^{\circ} \mathrm{C}$ & $T_{\mathrm{b}}-T_{\mathrm{f}},{ }^{\circ} \mathrm{C}$ \\
\hline S1 & Precipitation & $\begin{array}{l}\mathrm{pH}=6.00 \\
T=25^{\circ} \mathrm{C}\end{array}$ & $\begin{array}{c}258 \\
(104-276)\end{array}$ & 14.59 & $\begin{array}{c}354 \\
(321-397)\end{array}$ & 23.48 & 863 & $814-907$ \\
\hline S2 & $\begin{array}{l}\text { Heat treatment } \\
\text { of aluminum } \\
\text { nitrate }\end{array}$ & $\begin{array}{c}350^{\circ} \mathrm{C}, \\
1 \mathrm{~h}\end{array}$ & $\begin{array}{c}198 \\
(129-278)\end{array}$ & 1.53 & $\begin{array}{c}399 \\
(339-495)\end{array}$ & 8.89 & 884 & $855-911$ \\
\hline S3 & $\begin{array}{l}\text { Heat treatment } \\
\text { of hydrolysis } \\
\text { product }\end{array}$ & $\begin{array}{c}550^{\circ} \mathrm{C}, \\
2 \mathrm{~h}\end{array}$ & $\begin{array}{c}102 \\
(30-140)\end{array}$ & 10.69 & - & - & 799 & $683-882$ \\
\hline
\end{tabular}

Hereby, the method of the precipitation from a solution of aluminum nitrate with ammonia at $\mathrm{pH}=6.0$ without stabilization and aging (sample S1) allows for obtaining a complex amorphous compound in the form of a phase mixture that consists of amorphous aluminum hydroxide, basic aluminum salt, and poorly crystallized pseudoboehmite. 


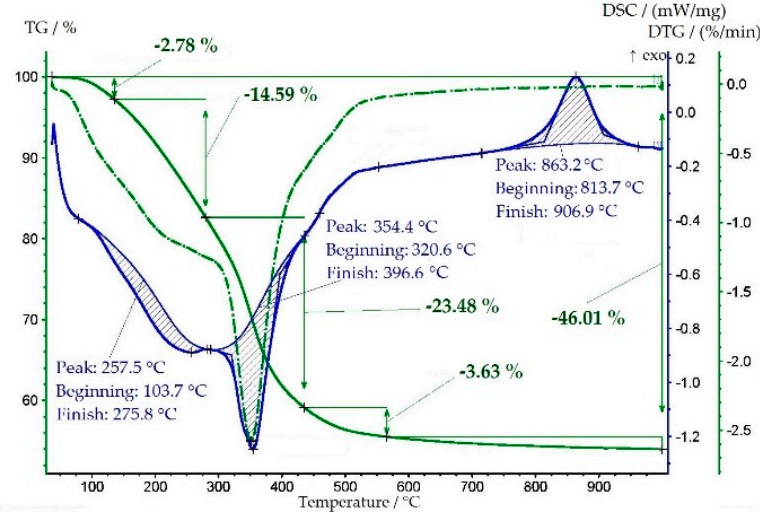

(a)

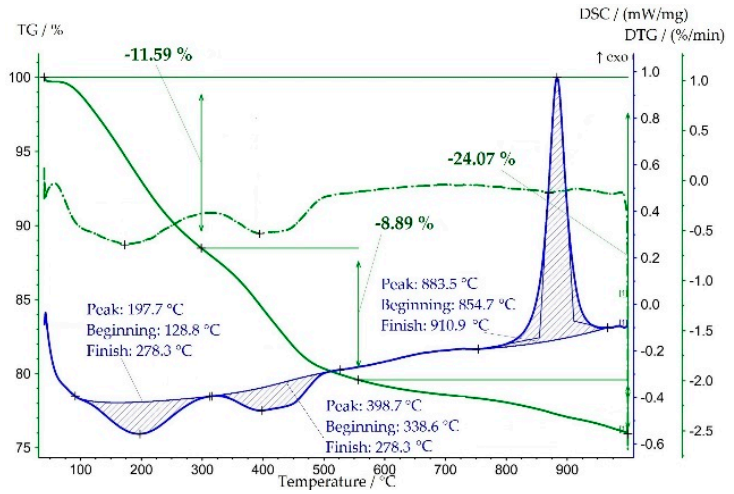

(c)

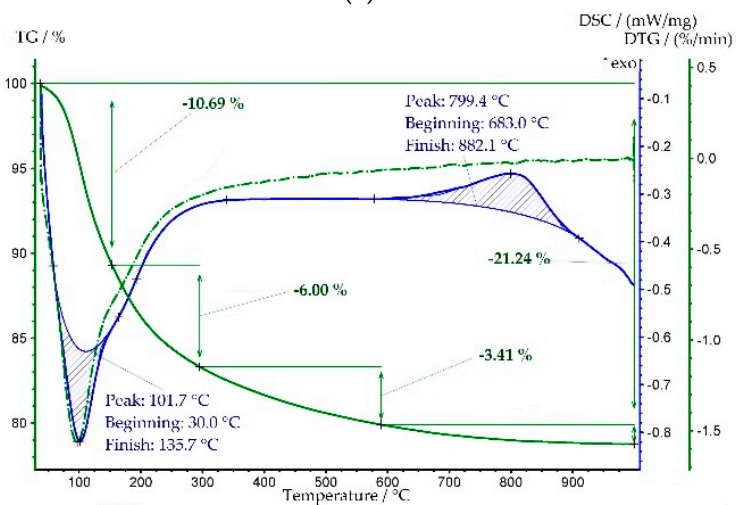

(e)

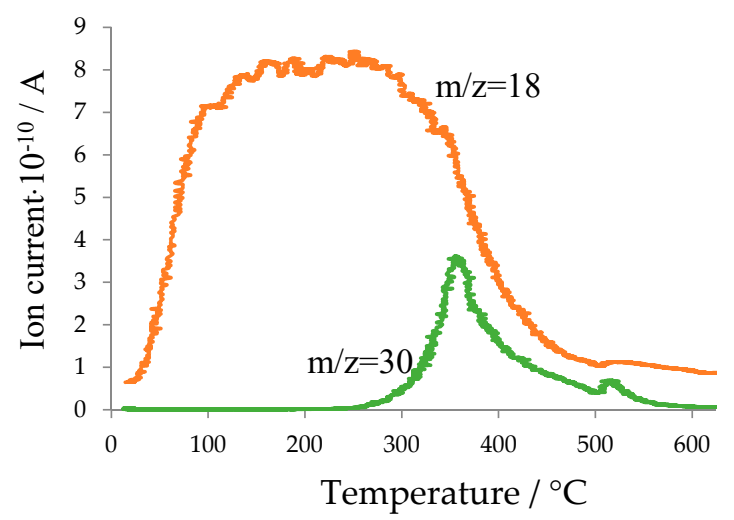

(b)

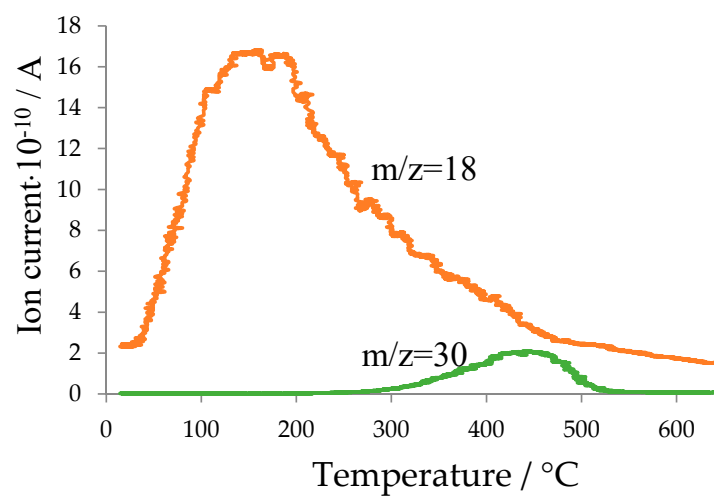

(d)

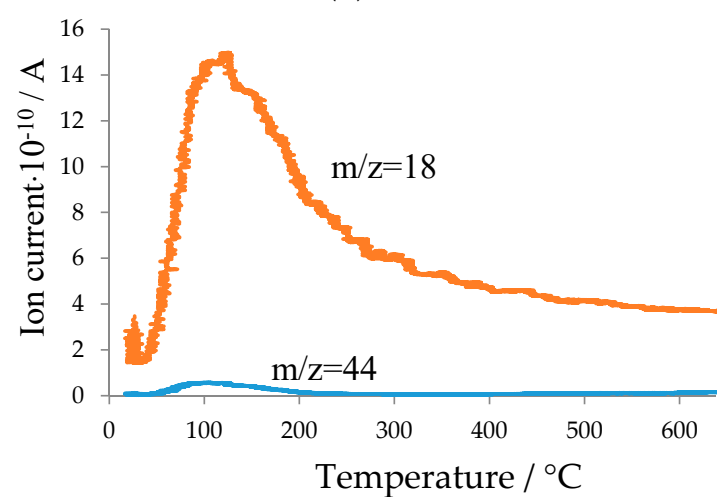

(f)

Figure 2. TG-DSC and MS analyses results of samples: S1 (a,b), S2 (c,d), S3 (e,f).

The quantitative phase composition of the complex precipitation product (S1) was calculated from the mass loss of the corresponding endothermic effects on the DSC curve and the areas of the NO peak in the mass spectrum (Figure 2a,b), since other nitrogen oxides are almost not observed. Based on the total nitrogen content in the sample (Table 1), the total amount of NO released from S1 during thermal decomposition to $650{ }^{\circ} \mathrm{C}$ is $9.79 \mathrm{wt} \%$. NO is exhibited by two peaks on S1 mass spectrum in the temperature range of II endothermic effect and its shoulder on the DSC curve of the sample in a ratio of 28.6:1.0 (Figure 2a,b). In this way, almost all nitrogen is released from the basic aluminum salt structure (only II endothermic effect). There is a possibility that the release of NO $0.32 \mathrm{wt} \%$ during thermal decomposition of $\mathrm{PB}$ is identified by the shoulder on DSC curve is due to the rearrangement of the hydroxide lattice to oxide ( $\mathrm{PB} \rightarrow \gamma-\mathrm{Al}_{2} \mathrm{O}_{3}$ ). $3.63 \mathrm{wt} \% \mathrm{H}_{2} \mathrm{O}$ is also released at the temperature. Since $\mathrm{PB}$ in the sample is poorly crystallized, as evidenced by diffuse diffraction lines (Figure 1), the value of interlayer water $n$ in its structure was taken as the maximum, i.e., $n=2.0$ [23]. In this case, the amount of $\mathrm{PB}$ in the sample $\mathrm{S} 1$ is $12.69 \mathrm{wt} \%$. 
Based on the total content of $\mathrm{NO}, 9.47$ wt $\% \mathrm{NO}$ and 14.01 wt $\% \mathrm{H}_{2} \mathrm{O}$ are released during thermal decomposition of the basic aluminum salt at the II endothermic effect, i.e., 0.32 and $0.78 \mathrm{~mol}$, respectively. Therefore, the empirical salt formula is $\mathrm{Al}_{2} \mathrm{O}_{3} \cdot 0.78 \mathrm{H}_{2} \mathrm{O} \cdot 0.32 \mathrm{NO}$.

It was reported in the following scientific works $[7,21,22]$ that the empirical formula amorphous aluminum hydroxide that was obtained by the precipitation of the aluminum salts by the base is $\mathrm{Al}_{2} \mathrm{O}_{3} \cdot 3 \mathrm{H}_{2} \mathrm{O}$. Its thermal decomposition begins at the temperature more than $200{ }^{\circ} \mathrm{C}$. Hence, the mass loss of I endothermic effect on the S1 DSC curve was divided into two parts, $8.18 \mathrm{wt} \% \mathrm{H}_{2} \mathrm{O}$, of which is physically adsorbed water $\left(<200{ }^{\circ} \mathrm{C}\right)$ and $6.41 \mathrm{wt} \% \mathrm{H}_{2} \mathrm{O}$ releases during the thermal decomposition of amorphous hydroxide. The calculated amount of basic aluminum salt and amorphous $\mathrm{Al}_{2} \mathrm{O}_{3} \cdot 3 \mathrm{H}_{2} \mathrm{O}$ in the sample $\mathrm{S} 1$ are $18.52 \mathrm{wt} \%$ and $60.61 \mathrm{wt} \%$, respectively.

According to the results of element, XRPD, TG-DSC, and MS analyses, the phase composition of the precipitation product (S1) calculated without taking into account physically adsorbed water is presented in Table 3.

Table 3. The phase composition of amorphous S1-S3 compounds.

\begin{tabular}{|c|c|c|c|c|}
\hline Sample & Obtaining Method & Conditions & Empirical Formula & Amount, wt \% \\
\hline S1 & Precipitation & $\begin{array}{l}\mathrm{pH}=6.00 \\
T=25^{\circ} \mathrm{C}\end{array}$ & $\begin{array}{c}\mathrm{Al}_{2} \mathrm{O}_{3} \cdot 3 \mathrm{H}_{2} \mathrm{O} \text { (amorphous hydroxide) } \\
\mathrm{Al}_{2} \mathrm{O}_{3} \cdot 0.78 \mathrm{H}_{2} \mathrm{O} \cdot 0.32 \mathrm{NO} \text { (basic salt) } \\
\mathrm{Al}_{2} \mathrm{O}_{3} \cdot 2 \mathrm{H}_{2} \mathrm{O}(\mathrm{PB})\end{array}$ & $\begin{array}{l}20.2 \\
66.0 \\
13.8\end{array}$ \\
\hline S2 & $\begin{array}{l}\text { Heat treatment of } \\
\text { aluminum nitrate }\end{array}$ & $\begin{array}{l}350{ }^{\circ} \mathrm{C}, \\
1 \mathrm{~h}\end{array}$ & $\begin{array}{l}\mathrm{Al}_{2} \mathrm{O}_{3} \cdot 3 \mathrm{H}_{2} \mathrm{O} \text { (amorphous hydroxide) } \\
\mathrm{Al}_{2} \mathrm{O}_{3} \cdot 0,29 \mathrm{H}_{2} \mathrm{O} \cdot 0,12 \mathrm{NO} \text { (basic salt) }\end{array}$ & $\begin{array}{l}16.3 \\
83.7\end{array}$ \\
\hline S3 & $\begin{array}{l}\text { Heat treatment of } \\
\text { hydrolysis product }\end{array}$ & $\begin{array}{l}550{ }^{\circ} \mathrm{C}, \\
2 \mathrm{~h}\end{array}$ & $\mathrm{Al}_{2} \mathrm{O}_{3}$ (amorphous oxide) & 100.0 \\
\hline
\end{tabular}

The method of thermal decomposition of aluminum nitrate $\mathrm{Al}\left(\mathrm{NO}_{3}\right)_{3} \cdot 9 \mathrm{H}_{2} \mathrm{O}$ at $350{ }^{\circ} \mathrm{C}$ for $1 \mathrm{~h}$ allows for obtaining a complex X-ray amorphous compound in the form of the phase mixture of aluminum hydroxide and basic salt in the amount of, respectively, 16.3 and $83.7 \mathrm{wt} \%$ (Table 3). These phases are exhibited by two corresponding endothermic effects on the S2 DSC curve and the release of $\mathrm{H}_{2} \mathrm{O}$ and $\mathrm{NO}$ on the MS spectrum (Table 2, Figure 2c,d).

The quantitative S2 composition was calculated, as in case of Sample S1, by the mass loss of endothermic effects on the S2 DSC curve (Table 2, Figure 2c,d). Based on the total nitrogen content in the sample (Table 1), the total amount of released NO is $3.66 \mathrm{wt} \%$. The amount of amorphous aluminum hydroxide $\left(\mathrm{Al}_{2} \mathrm{O}_{3} \cdot 3 \mathrm{H}_{2} \mathrm{O}\right)$ was calculated based on mass loss on the $\mathrm{S} 2 \mathrm{DSC}$ curve more than $200{ }^{\circ} \mathrm{C}$ and equaled $16.27 \mathrm{wt} \%$. Based on the total content of $\mathrm{NO}(3.66 \mathrm{wt} \%)$ and the mass spectrum of sample S2 (Figure 2d), the release of NO occurs only during the thermal decomposition of salt (II endothermic effect) and $5.23 \mathrm{wt} \% \mathrm{H}_{2} \mathrm{O}$ is also released, i.e., respectively 0.12 and $0.29 \mathrm{~mol}$. Consequently, the empirical formula of the basic aluminum salt is $\mathrm{Al}_{2} \mathrm{O}_{3} \cdot 0.29 \mathrm{H}_{2} \mathrm{O} \cdot 0.12 \mathrm{NO}$.

The thermal decomposition method of the product of aluminum alcoxide hydrolysis at $550{ }^{\circ} \mathrm{C}$ for $2 \mathrm{~h}$ (sample S3) allows for obtaining a phase-homogeneous X-ray amorphous alumina, which has a small amount of metal impurities (Table 1). Residual organic compounds are exhibited by a pronounced shoulder of the I endothermic effect in the low-temperature region on the S3 DSC curve and the presence in the mass spectrum of peaks, corresponding to the release of $\mathrm{CO}_{2}$ and $\mathrm{H}_{2} \mathrm{O}$ (Figure 2e,f).

The precipitation method $(\mathrm{pH}=6.0)$ allows for obtaining the mixture of particles $(\sim 100 \mu \mathrm{m})$, the surface of which consists of thin plates of size to $1 \mu \mathrm{m}$ layering on each other closely, with extended cracks resulting from drying the gel-like precipitate [7,21] (Figure 3a,b). It is impossible to identify the porous system of S1 in the SEM images. Indeed, according to the data of low-temperature nitrogen adsorption, sample $\mathrm{S} 1$ has a specific surface area $<1 \mathrm{~m}^{2} / \mathrm{g}$ and a pore volume $<0.01 \mathrm{~cm}^{3} / \mathrm{g}$ (Table 4 ). 


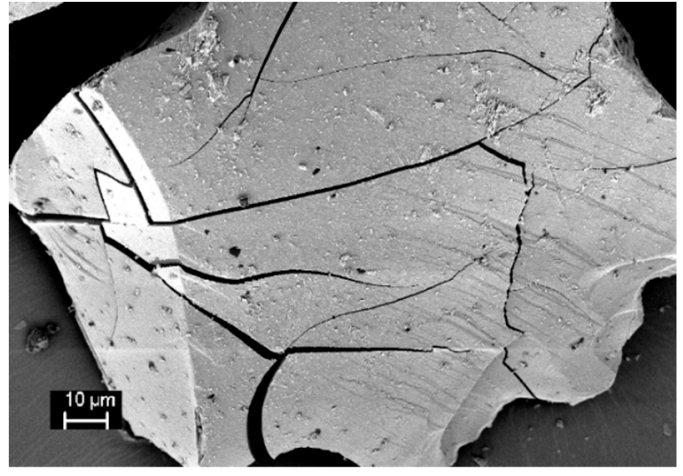

(a)

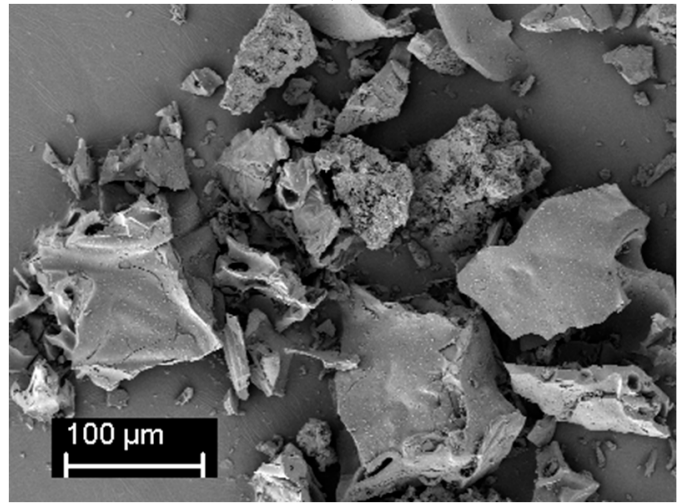

(c)

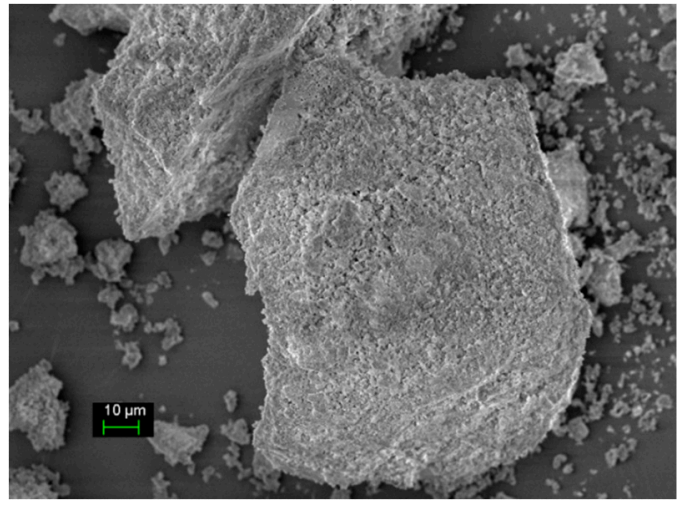

(e)

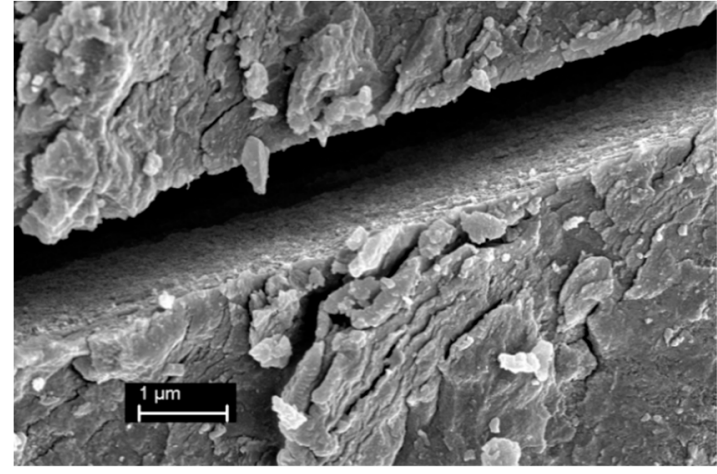

(b)

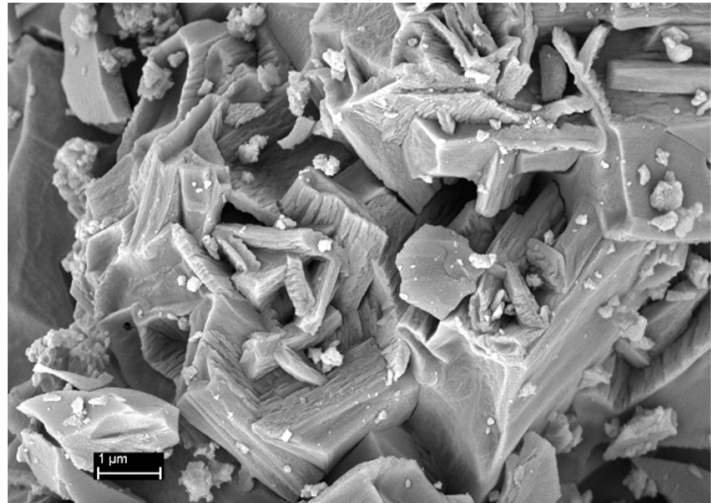

(d)

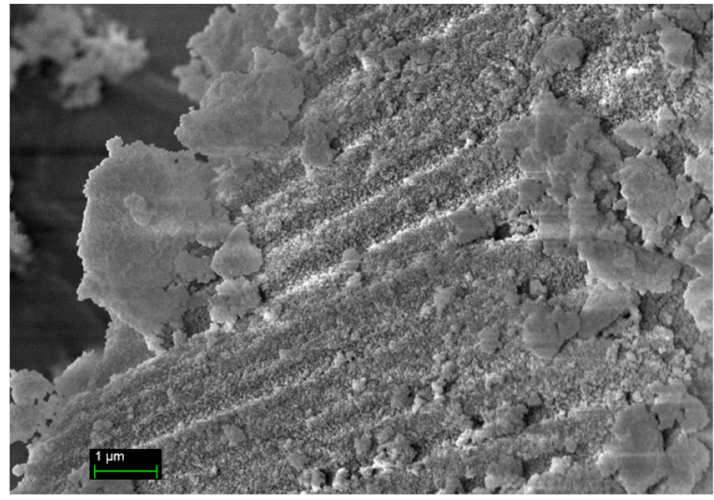

(f)

Figure 3. Scanning electron microscopy (SEM) images of external and internal surface of samples S1 $(\mathbf{a}, \mathbf{b}), \mathrm{S} 2(\mathbf{c}, \mathbf{d}), \mathrm{S} 3(\mathbf{e}, \mathbf{f})$.

The heat-treated product of $\mathrm{Al}\left(\mathrm{NO}_{3}\right)_{3} \cdot 9 \mathrm{H}_{2} \mathrm{O}$ (sample S2) is a mesoporous compound (as shown in the Figure S2 in the Supplementary Material), which has S and V of $29 \mathrm{~m}^{2} / \mathrm{g}$ and $0.04 \mathrm{~cm}^{3} / \mathrm{g}$, respectively (Table 4, Figure 4a). S2 particles are irregularly shaped particles of $>100 \mu \mathrm{m}$ (Figure 3c). The external surface is smooth, it has a size of 50-100 $\mu \mathrm{m}$, and it contains small fragments with cavities. The internal surface of S2 particles includes large cavities in the form of hemispheres with 5-10 $\mu \mathrm{m}$ diameters, sponge-like structure with cavity sizes of 50-850 nm, and it accretes plate-like particles between which conical spaces with a base diameter less than $530 \mathrm{~nm}$ are formed (Figure 3d). As shown on the SEM images (Figure 3c,d), sample S2 has the cavities formed, probably at the intense releasing of water and nitrogen oxide molecules during the thermal decomposition of nitrate. The cavities are distributed throughout the sample. Therefore, almost uniform distribution of $\mathrm{V}_{\mathrm{BJH}}$ pore diameters is observed (Table 4).

Heat treatment at $550{ }^{\circ} \mathrm{C}$ of the hydrolysis product makes it possible to obtain a highly porous sample with a high acidity of the surface (Table 2; Table 4, Figure 4b). Sample S3 particles are the 
large particles of 3-133 $\mu \mathrm{m}$, which consist of aggregates of irregularly shaped plates (Figure 3e). The aggregates are formed by small particles of $10-30 \mathrm{~nm}$. There are narrow and large cavities, respectively, of $<9 \mathrm{~nm}$ and $0.3-2.5 \mu \mathrm{m}$ between them.

Table 4. Porous system parameters of amorphous compounds S1-S3.

\begin{tabular}{|c|c|c|c|c|c|c|c|c|c|}
\hline \multirow[t]{2}{*}{ Sample } & \multirow{2}{*}{$\begin{array}{l}\text { Obtaining } \\
\text { Method }\end{array}$} & \multirow{2}{*}{ Conditions } & \multirow{2}{*}{$\begin{array}{c}S, \\
\left(\mathrm{~m}^{2} / \mathrm{g}\right)\end{array}$} & \multirow{2}{*}{$\begin{array}{c}V, \\
\left(\mathrm{~cm}^{3} / \mathrm{g}\right)\end{array}$} & \multirow{2}{*}{$\begin{array}{l}V_{\mathrm{BJH}}, \\
\left(\mathrm{cm}^{3} / \mathrm{g}\right)\end{array}$} & \multicolumn{3}{|c|}{$\begin{array}{c}\text { Distribution of } V_{\mathrm{BJH}} \\
\text { over } D_{\mathrm{p}}, \mathrm{cm}^{3} / \mathrm{g}(\%)\end{array}$} & \multirow{2}{*}{$\begin{array}{c}D_{\max ,}(\mathrm{nm}) \\
\mathrm{d} V / \mathrm{d} D, \\
\left(\mathrm{~cm}^{3} / \mathrm{g} \cdot \mathrm{nm}\right)\end{array}$} \\
\hline & & & & & & $<3 \mathrm{~nm}$ & $3-10 \mathrm{~nm}$ & $>10 \mathrm{~nm}$ & \\
\hline S1 & Precipitation & $\begin{array}{l}\mathrm{pH}=6.00 \\
T=25^{\circ} \mathrm{C}\end{array}$ & $<1$ & $<0.01$ & $<0.01$ & - & - & - & - \\
\hline S2 & $\begin{array}{c}\text { Heat treatment } \\
\text { of aluminum } \\
\text { nitrate }\end{array}$ & $\begin{array}{l}350{ }^{\circ} \mathrm{C} \\
1 \mathrm{~h}\end{array}$ & 29 & 0.04 & 0.05 & $\begin{array}{l}0.02 \\
(40)\end{array}$ & $\begin{array}{l}0.02 \\
(40)\end{array}$ & $\begin{array}{l}0.01 \\
(20)\end{array}$ & $3.7 / 0.02$ \\
\hline S3 & $\begin{array}{c}\text { Heat treatment } \\
\text { of hydrolysis } \\
\text { product }\end{array}$ & $\begin{array}{c}550^{\circ} \mathrm{C} \\
2 \mathrm{~h}\end{array}$ & 344 & 0.90 & 0.95 & $\begin{array}{c}0.01 \\
(1)\end{array}$ & $\begin{array}{l}0.56 \\
(59)\end{array}$ & $\begin{array}{l}0.38 \\
(40)\end{array}$ & $4.5 / 0.19$ \\
\hline
\end{tabular}

In the crack of aggregate, parallel channels with a diameter of $280-360 \mathrm{~nm}$ are formed (Figure 3f), the entrance to which is the larger wells of $\sim 400 \mathrm{~nm}$ diameter on the external surface of particle. Despite the absence of micropores, sample S3 has high S $\left(344 \mathrm{~m}^{2} / \mathrm{g}\right)$, which includes $59 \%$ pores with $D_{\mathrm{p}}=3-10 \mathrm{~nm}$ (as shown in the Figure S2 in the Supplementary Material and Table 4). Probably, the narrow pores with $D_{\mathrm{p}}=4.5 \mathrm{~nm}$ of the sample are the spaces between the primary particles of alumina. The cavities are pores with $D_{\mathrm{p}}>10 \mathrm{~nm}$, which consist of $40 \%$ of the S3 porous system.

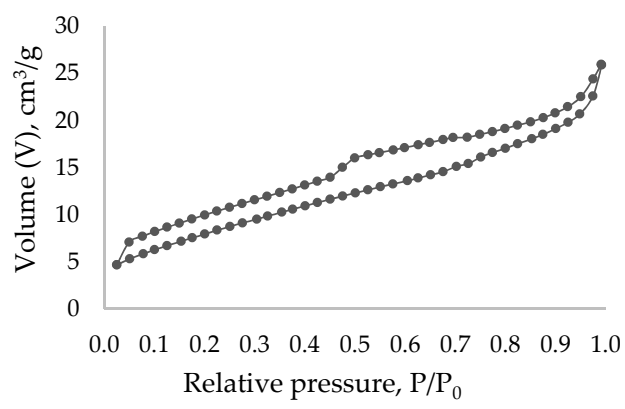

(a)

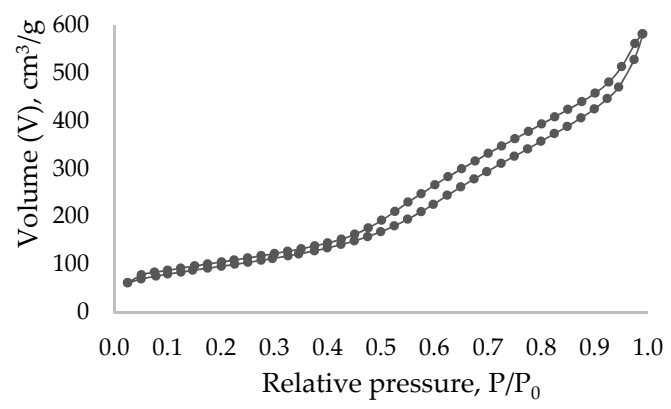

(b)

Figure 4. Isotherms of samples S2 (a) and S3 (b).

Acid and base sites possessing various structure and strength are presented on the surface of alumina obtained by the heat treatment (HT) of the amorphous aluminum compounds. The distribution of sites is mainly caused by the phase composition of a compound. Acid sites are Brønsted-type (terminal or bridge surface hydroxyl groups) and Lewis (coordination-unsaturated aluminum cations) centers [24,25]. Both types of acid sites are identified by various methods one of which is the TPD of $\mathrm{NH}_{3}$ method. It allows for determining the total acidity of the surface. However, the proton affinity energy of the strongest Brønsted sites of alumina is not sufficient for the protonation of ammonia molecules [26].

After dehydration, the Lewis acid and basic sites are simultaneously formed on the surface of the alumina. Lewis acid sites transform into Brønsted sites in the presence of water molecules [27]: 


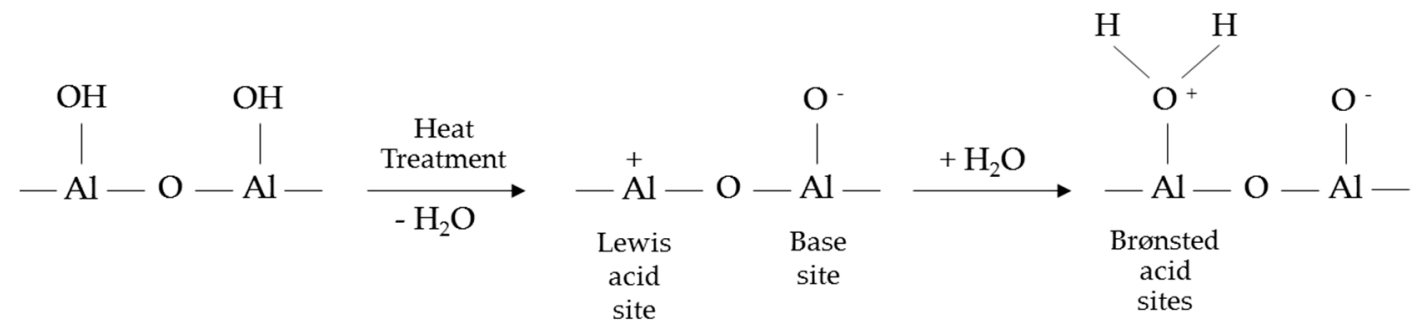

Interacting the $\mathrm{NH}_{3}$ molecule with Lewis acid sites forms a coordination (donor-acceptor) bond due to the free electron pair of the nitrogen atom:

$$
\equiv \mathrm{Al} \ldots \mathrm{NH}_{3}
$$

For studying the samples' acid properties, S1 and S2 were previously heat treated (HT) at the $550{ }^{\circ} \mathrm{C}$ to remove excess water in the form of hydroxyl groups from the surfaces. Sample S3 was not additionally treated because it was obtained by heating at $550{ }^{\circ} \mathrm{C}$. The TPD curves of $\mathrm{NH}_{3}$ samples are presented in Figure 5. The distribution of acid sites (a.s.) according to the ammonia desorption energy $\left(E_{\mathrm{d}}\right)$ for the obtained samples is given in Table 5. The a.s. with $E_{\mathrm{d}}<110 \mathrm{~kJ} / \mathrm{mol}$, which corresponds to the desorption temperature up to $210{ }^{\circ} \mathrm{C}$, were attributed to the weak strength sites. The a.s. with $E_{\mathrm{d}}$ to 110 to $142 \mathrm{~kJ} / \mathrm{mol}$ and $E_{\mathrm{d}}>142 \mathrm{~kJ} / \mathrm{mol}$ are, respectively, taken for the medium (desorption temperature of $210-350{ }^{\circ} \mathrm{C}$ ) and the strong strength sites (desorption temperature is more than $350{ }^{\circ} \mathrm{C}$ ).

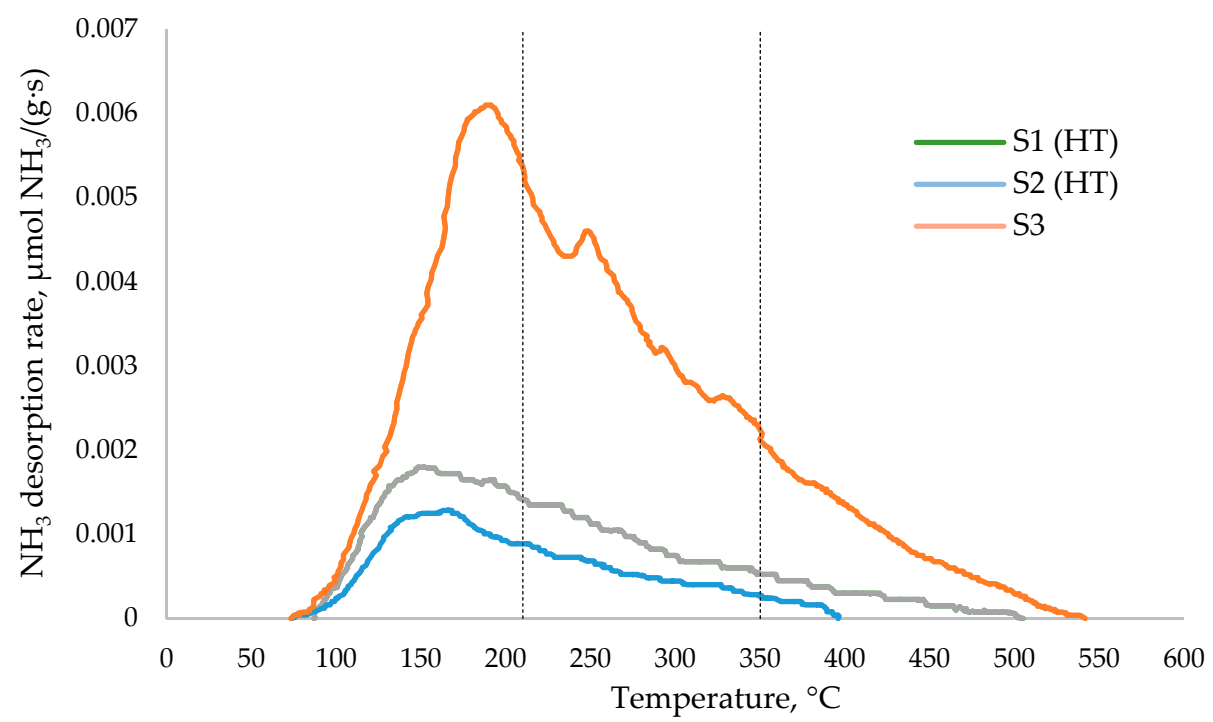

Figure 5. Curves of the temperature-programmed desorption (TPD) of ammonia of samples (HT-heat treated).

TPD-NH $\mathrm{N}_{3}$ curves of all samples begin from the temperature of $\sim 75{ }^{\circ} \mathrm{C}$ (Figure 5). Diffuse peaks are noted to the dependences of the ammonia desorption rate on the temperature of $\mathrm{S}_{1}{ }^{\mathrm{HT}}$ and $\mathrm{S} 2{ }^{\mathrm{HT}}$ samples in the region of $\sim 140-190^{\circ} \mathrm{C}$. An intensive peak is noted on the curve of S3. These peaks are characterized by weak a.s. In the area of medium a.s. of $\mathrm{S}^{\mathrm{HT}}$ and $\mathrm{S} 2{ }^{\mathrm{HT}}$ samples, the ammonia desorption rate with increasing temperature decreases slowly, while the desorption rate on the S3 curve increases with a peak at the temperature of $235-250{ }^{\circ} \mathrm{C}$. In the field of strong a.s., an equable decrease in the desorption rate to 400,500 , and $540^{\circ} \mathrm{C}$ occurs for samples $\mathrm{S}^{\mathrm{HT}}, \mathrm{S} 2{ }^{\mathrm{HT}}$, and $\mathrm{S} 3$, respectively. 
Table 5. Ammonia $\left(\mathrm{NH}_{3}\right)$ TPD acid characteristics of samples $\mathrm{S}^{\mathrm{HT}}, \mathrm{S} 2 \mathrm{HT}$, and $\mathrm{S} 3$.

\begin{tabular}{|c|c|c|c|c|c|c|}
\hline \multirow{2}{*}{ Sample } & \multirow{2}{*}{ Obtaining Method } & \multirow[b]{2}{*}{ Conditions } & \multicolumn{4}{|c|}{ Number of a.s., $\mu \mathrm{mol} \mathrm{NH}_{3} / \mathrm{g}$} \\
\hline & & & $\begin{array}{l}E_{\mathrm{d}}<110 \\
(\mathrm{~kJ} / \mathrm{mol})\end{array}$ & $\begin{array}{c}110<E_{\mathrm{d}}< \\
142,(\mathrm{~kJ} / \mathrm{mol})\end{array}$ & $\begin{array}{l}E_{\mathrm{d}}>142 \\
(\mathrm{~kJ} / \mathrm{mol})\end{array}$ & Total \\
\hline $\mathrm{S} 1^{\mathrm{HT}}$ & Precipitation & $\begin{array}{l}\mathrm{pH}=6.00 \\
T=25^{\circ} \mathrm{C}\end{array}$ & 99.1 & 77.8 & 23.3 & 200.2 \\
\hline $\mathrm{S} 2^{\mathrm{HT}}$ & $\begin{array}{l}\text { Heat treatment of } \\
\text { aluminum nitrate }\end{array}$ & $\begin{array}{l}350^{\circ} \mathrm{C}, \\
1 \mathrm{~h}\end{array}$ & 45.6 & 63.2 & 7.1 & 115.9 \\
\hline S3 & $\begin{array}{l}\text { Heat treatment of } \\
\text { hydrolysis product }\end{array}$ & $\begin{array}{l}550{ }^{\circ} \mathrm{C}, \\
2 \mathrm{~h}\end{array}$ & 150.9 & 427.6 & 73.7 & 652.2 \\
\hline
\end{tabular}

In the case of a precipitation product $\mathrm{S}^{\mathrm{HT}}$, the intermediate value of acidity in comparison with $\mathrm{S}_{2}{ }^{\mathrm{HT}}$ and $\mathrm{S} 3$ samples is due to the content of $\mathrm{Li}, \mathrm{Na}, \mathrm{Mg}$ and Fe impurity ions (Table 1). Also, after the heat treatment of basic aluminum salts, a small amount of a.s. on the surface of the amorphous oxide is probably due to the formation of the base sites during the removing of $\mathrm{NO}$ and $\mathrm{H}_{2} \mathrm{O}$ molecules to the following scheme:
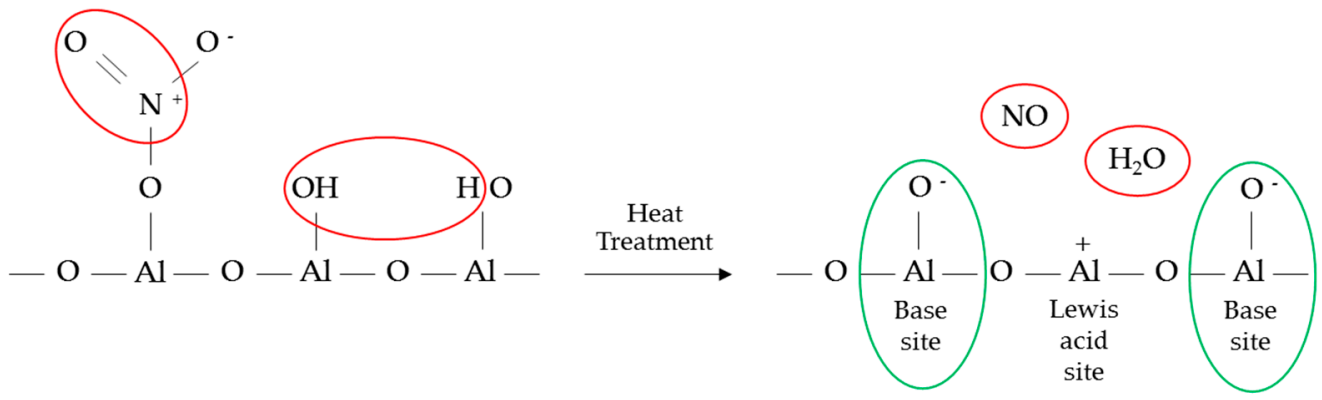

$\gamma-\mathrm{Al}_{2} \mathrm{O}_{3}$ also contributes to the total a.s. quantity [25]. Indeed, $\mathrm{S}^{\mathrm{HT}}$ contains the strong a.s. and medium a.s. in amounts of $12 \%$ and $38 \%$, respectively (Table 5 ).

After heat treatment of the sample S2, amorphous hydroxide and basic aluminum salt form amorphous alumina that possesses a small amount of a.s., $96 \%$ of which are weak and medium strength (Table 5, Figure 5). As previously noted, this effect is observed due to the high content of $\mathrm{Na}, \mathrm{Mg}$, and Fe impurity ions (Table 1). Also, the small amount of a.s. is probably due to the formation of base sites during the removal of $\mathrm{NO}$ and $\mathrm{H}_{2} \mathrm{O}$ molecules after the thermal decomposition of nitrogen-containing basic aluminum salts.

Amorphous alumina obtained by thermal decomposition of the alcoxide hydrolysis product has a large number of a.s. on the surface, $65 \%$ of which is medium strength (Table 4 ). S3 consists of the small amount of $\mathrm{Na}$ (Table 1) and the impurities do not block a.s. its surface as against the $\mathrm{S}^{\mathrm{HT}}$ and $\mathrm{S}^{\mathrm{HT}}$. In addition, during the heat treatment of the hydrolysis product, thermal decomposition of underhydrolyzed alcoholate occurs with the formation of $\mathrm{CO}_{2}$ molecules, the $\mathrm{O}^{-}$atom of which was probably bended with Al. Hence, the Lewis a.s. is formed according to the following scheme:

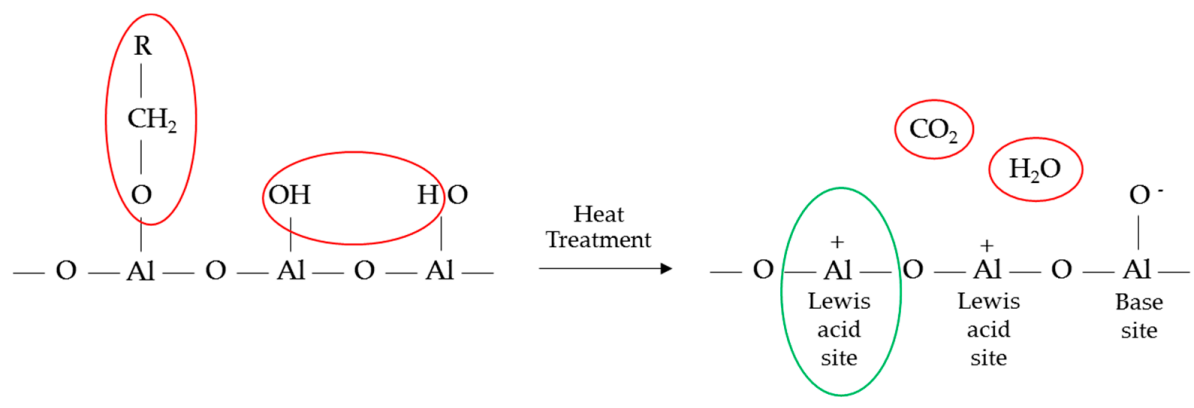




\section{Conclusions}

The comparative analysis of amorphous aluminum compounds obtained by the precipitation method, the thermal decomposition of aluminum nitrate and alcoxide hydrolysis product, and their physicochemical properties were studied. For the first time a new method for calculating quantitative phase composition of amorphous aluminum compounds using a group of methods as XPRD, TG-DSC, MS, and CHN-analysis was described.

The method of precipitation of $0.25 \mathrm{~g} / \mathrm{mL}$ of aluminum nitrate by ammonia solution at $\mathrm{pH}=6.0$ without aging and stabilization stages allows for obtaining a complex amorphous aluminum compound, which includes amorphous hydroxide $\left(\mathrm{Al}_{2} \mathrm{O}_{3} \cdot 3 \mathrm{H}_{2} \mathrm{O}\right)$, basic salt $\left(\mathrm{Al}_{2} \mathrm{O}_{3} \cdot 0.78 \mathrm{H}_{2} \mathrm{O} \cdot 0.32 \mathrm{NO}\right)$, and pseudoboehmite $\left(\mathrm{Al}_{2} \mathrm{O}_{3} \cdot 2 \mathrm{H}_{2} \mathrm{O}\right)$. This compound is non-porous, its particles has large cracks. For the heat-treated precipitation product, which is a mixture of amorphous alumina and $\gamma$-alumina, is characterized by the total number of a.s. of $200.2 \mu \mathrm{mol} / \mathrm{g}$ containing $12 \%$ strong and $50 \%$ weak acid sites on its surface due to the presence in the sample of $\mathrm{Li}, \mathrm{Na}, \mathrm{Mg}$, and $\mathrm{Fe}$ impurity ions.

The method of thermal decomposition of aluminum nitrate at $350{ }^{\circ} \mathrm{C}$ for $1 \mathrm{~h}$ allows for obtaining a complex amorphous aluminum compound, which includes amorphous hydroxide $\left(\mathrm{Al}_{2} \mathrm{O}_{3} \cdot 3 \mathrm{H}_{2} \mathrm{O}\right)$ and basic salt $\left(\mathrm{Al}_{2} \mathrm{O}_{3} \cdot 0.29 \mathrm{H}_{2} \mathrm{O} \cdot 0.12 \mathrm{NO}\right)$. This compound is mesoporous with the low specific surface area and pore volume, a maximum on the differential distribution curve of pore volumes over the pore diameter is $3.7 \mathrm{~nm}$. The product of thermal decomposition of nitrate is a monolithic irregularly shaped particle with cavities that were evenly distributed throughout the sample. The thermal decomposition of the sample leads to amorphous oxide, which is accompanied by the formation of a small quantity of acid sites on its surface, which contains $6 \%$ strong and $55 \%$ medium sites due to the high content of $\mathrm{Na}, \mathrm{Mg}$, and Fe impurities in the sample.

The method of heat treatment at $550{ }^{\circ} \mathrm{C}$ for $2 \mathrm{~h}$ of the hydrolysis product of the alcoxide allows for obtaining a monophasic amorphous alumina. It is highly porous with high specific surface area and pore volume, a maximum on the distribution curve of pore volumes over diameters is $4.5 \mathrm{~nm}$. Amorphous alumina is a large aggregates formed by small particles, between which are narrow and large cavities. It has a large quantity of acid sites on the surface, which is $65 \%$ medium and $12 \%$ strong sites due to the small amount of impurities in the sample.

Supplementary Materials: The following are available online at http://www.mdpi.com/2079-6412/9/1/41/s1, Figure S1. Diffractogram and thermal curves of amorphous aluminum hydroxide obtained by the hydrolysis (S3 sample precursor); Figure S2. The curves of distribution of $\mathrm{V}_{\mathrm{BJH}}$ with $\mathrm{D}_{\mathrm{p}}$ of samples S2 (a) and S3 (b).

Author Contributions: Conceptualization, A.N.M. and S.R.E.; Methodology, S.R.E. and A.A.L.; Validation, A.N.M., S.R.E. and A.A.L.; Formal Analysis, O.V.N., K.S.B., A.V.B. and J.S.; Investigation, A.N.M. and A.V.B.; Resources, A.A.L.; Data Curation, A.N.M.; Writing-Original Draft Preparation, A.N.M.; Writing-Review \& Editing, A.N.M.; Visualization, A.N.M.; Supervision, S.R.E. and A.A.L.; Project Administration, A.N.M. and S.R.E.; Funding Acquisition, A.N.M. and A.A.L.

Funding: The reported study of samples S1 and S2 (products of precipitation aluminum nitrate by ammonia solution and thermal decomposition of aluminum nitrate) was funded by RFBR according to the research project No. 18-33-00559. The study of sample S3 (product of thermal decomposition of aluminum hydroxide obtained by the organoaluminum compounds hydrolysis) was performed according to the Russian Government Program of Competitive Growth of Kazan Federal University.

Acknowledgments: The thermal analysis of samples was carried out at the Federal Center for Collective Use of the Kazan Federal University with the support of the Russian Agency for Science and Innovation A.V. Gerasimov. The scanning electron microscopy measurements were performed at the Interdisciplinary Center "Analytical Microscopy" of the Kazan Federal University V.V. Vorobiev and V.G. Evtyugin respectively.

Conflicts of Interest: The authors declare no conflict of interest. 


\section{References}

1. Ivanova, A.S.; Litvak, G.S.; Kryukova, G.N.; Tsybulya, S.V.; Paukshtis, E.A. Real structure of metastable forms of aluminum oxide. Kinet. Catal. 2000, 41, 122-126. [CrossRef]

2. Macêdo, M.I.F.; Osawa, C.C.; Bertran, C.A. Sol-gel synthesis of transparent alumina gel and pure gamma alumina by urea hydrolysis of aluminum nitrate. J. Sol-Gel Sci. Technol. 2004, 30, 135-140. [CrossRef]

3. Garbarino, G.; Travi, I.; Pani, M.; Carnasciali, M.M.; Busca, G. Pure vs ultra-pure $\gamma$-alumina: A spectroscopic study and catalysis of ethanol conversion. Catal. Commun. 2015, 70, 77-81. [CrossRef]

4. Novak, C.; Pokol, G.; Izvekov, V.; Gal, T. Studies on the reactions of aluminium oxides and hydroxides. J. Therm. Anal. 1990, 36, 1895-1909. [CrossRef]

5. Nayar, P.; Khanna, A.; Kabiraj, D.; Abhilash, S.R.; Beake, B.D.; Losset, Y.; Chen, B. Structural, optical and mechanical properties of amorphous and crystalline alumina thin films. Thin Solid Films 2014, 568, 19-24. [CrossRef]

6. Pacewska, B.; Keshr, M. Thermal transformations of the products of partial hydrolysis of hydrous aluminium nitrate. J. Therm. Anal. Calorim. 2004, 75, 113-123. [CrossRef]

7. Landau, M.V. Sol-Gel Processing. In Synthesis of Solid Catalysts; de Jong, K.P., Ed.; Wiley-VCH: Weinheim, German, 2009; pp. 83-109.

8. Oh, C.J.; Yi, Y.K.; Kim, S.J.; Tran, T.; Kim, M.J. Production of micro-crystalline boehmite from hydrothermal processing of Bayer plant alumina tri-hydrate. Powder Technol. 2013, 235, 556-562. [CrossRef]

9. Tsuchida, T. Hydrothermal synthesis of submicrometer crystals of boehmite. J. Eur. Ceram. Soc. 2000, 20, 1759-1764. [CrossRef]

10. Yoldas, B.E. Hydrolysis of aluminium alkoxides and bayerite conversion. J. Appl. Chem. Biotechnol. 1973, 23, 803-809. [CrossRef]

11. Hwang, K.T.; Lee, H.S.; Lee, S.H.; Chung, K.C.; Park, S.S.; Lee, J.H. Synthesis of aluminium hydrates by a precipitation method and their use in coatings for ceramic membranes. J. Eur. Ceram. Soc. 2001, 21, 375-380. [CrossRef]

12. Lippens, B.C.; de Boer, J.H. Studies on pore systems in catalysts: V. The t method. J. Catal. 1965, 4, 319-323. [CrossRef]

13. Ma, C.C.; Zhou, X.X.; Xu, X.; Zhu, T. Synthesis and thermal decomposition of ammonium aluminum carbonate hydroxide (AACH). Mater. Chem. Phys. 2001, 72, 374-379. [CrossRef]

14. Mukhambetov, I.N.; Egorova, S.R.; Mukhamed'yarova, A.N.; Lamberov, A.A. Hydrothermal modification of the alumina catalyst for the skeletal isomerization of n-butenes. Appl. Catal. A 2018, 554, 64-70. [CrossRef]

15. Lehmkuhl, H. Organoaluminum compounds. Ann. New York Acad. Sci. 1965, 125, 124-130. [CrossRef]

16. Hayrapetyan, S.S.; Mangasaryan, L.G.; Tovmasyan, M.R.; Khachatryan, H.G. Precipitation of aluminum hydroxide from sodium aluminate, by treatment with formalin, and preparation of aluminum oxide. Acta Chromatogr. 2006, 16, 192. [CrossRef]

17. GOST 3757-75 Reaktivy Alyuminij azotno-kislyj 9-vodnyj. Tekhnicheskie usloviya; Standartinform Publ.: Moscow, Russia, 1993. (In Russian)

18. Gregg, S.J. Adsorption, Surface Area and Porosity; Academic Press: London, UK, 1982.

19. Bronsted, J.N. Acid and Basic Catalysis. Chem. Rev. 1928, 5, 231-338. [CrossRef]

20. Von Hehl, A.; Krug, P. Aluminum and Aluminum Alloys. In Structural Materials and Processes in Transportation; Lehmhus, D., Busse, M., Herrmann, A.S., Kayvantash, K., Eds.; Wiley-VCH: Weinheim, German, 2013.

21. Du, X.; Wang, Y.; Su, X.; Li, J. Influences of $\mathrm{pH}$ value on the microstructure and phase transformation of aluminum hydroxide. Powder Technol. 2009, 192, 40-46. [CrossRef]

22. Zhang, X.; Honkanen, M.; Levänen, E.; Mäntylä, T. Transition alumina nanoparticles and nanorods from boehmite nanoflakes. J. Cryst. Growth 2008, 310, 3674-3679. [CrossRef]

23. de Boer, J.H.; Linsen, B.G.; Osinga, T.J. Studies on pore systems in catalysts: VI. The universal t curve. J. Catal. 1965, 4, 643-648. [CrossRef]

24. Digne, M.; Sautet, P.; Raybaud, P.; Euzen, P.; Toulhoat, H. Hydroxyl groups on $\gamma$-alumina surfaces: A DFT study. J. Catal. 2002, 211, 1-5. [CrossRef]

25. Tago, T.; Okubo, Y.; Mukai, S.R.; Tanaka, T.; Masuda, T. Simultaneous characterization of acidic and basic properties of solid catalysts by a new TPD method and their correlation to reaction rates. Appl. Catal. A 2005, 290, 54-64. [CrossRef] 
26. El-Nadjar, W.; Bonne, M.; Trela, E.; Rouleau, L.; Mino, A.; Hocine, S.; Payen, E.; Lancelot, C.; Lamonier, C.; Blanchard, P.; Courtois, X.; Can, F.; Duprez, D.; Royer, S. Infrared investigation on surface properties of alumina obtained using recent templating routes. Microporous Mesoporous Mater. 2012, 158, 88-98. [CrossRef]

27. Phung, T.K.; Proietti Hernández, L.; Lagazzo, A.; Busca, G. Dehydration of ethanol over zeolites, silica alumina and alumina: Lewis acidity, Brønsted acidity and confinement effects. Appl. Catal. A 2015, 493, 77-89. [CrossRef]

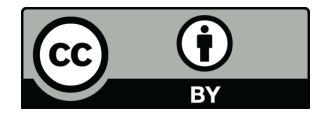

(C) 2019 by the authors. Licensee MDPI, Basel, Switzerland. This article is an open access article distributed under the terms and conditions of the Creative Commons Attribution (CC BY) license (http:/ / creativecommons.org/licenses/by/4.0/). 